\title{
Optimal decision making with biologically realistic neural signals
}

\author{
Javier A Caballero*, Kevin N Gurney \\ From Nineteenth Annual Computational Neuroscience Meeting: CNS*2010 \\ San Antonio, TX, USA. 24-30 July 2010
}

Action selection in animals requires rapid decision making that can discriminate the most salient requests for behavioral expression. The basal ganglia (BG) are believed to play a critical role in resolving competition between these requests [1] and, recently it has been proposed that the BG and cortex, taken together, implement a decision algorithm known as the multi-hypothesis sequential probability ratio test (MSPRT) [2]. Here, the cortex first integrates noisy 'evidence' indicating salience of action requests. The BG then examine this integrated evidence, and report the channel with maximal mean salience. The MSPRT is optimal in the sense that it guarantees the smallest decision time for a given error. The signals used in [2] assume cortical evidence - as neural firing rates - is supplied by Gaussian distributed signals. However, it is known that such rates are not distributed normally.

To remedy this we have deduced three new forms for MSPRT that are based on more biologically realistic input signals. They include the Inverse Gaussian, Gamma and Lognormal distributions. All implementations preserve a form which could be mapped, in principle, onto the anatomy of the BG. Figure 1 shows an example of the performance of the MSPRT models

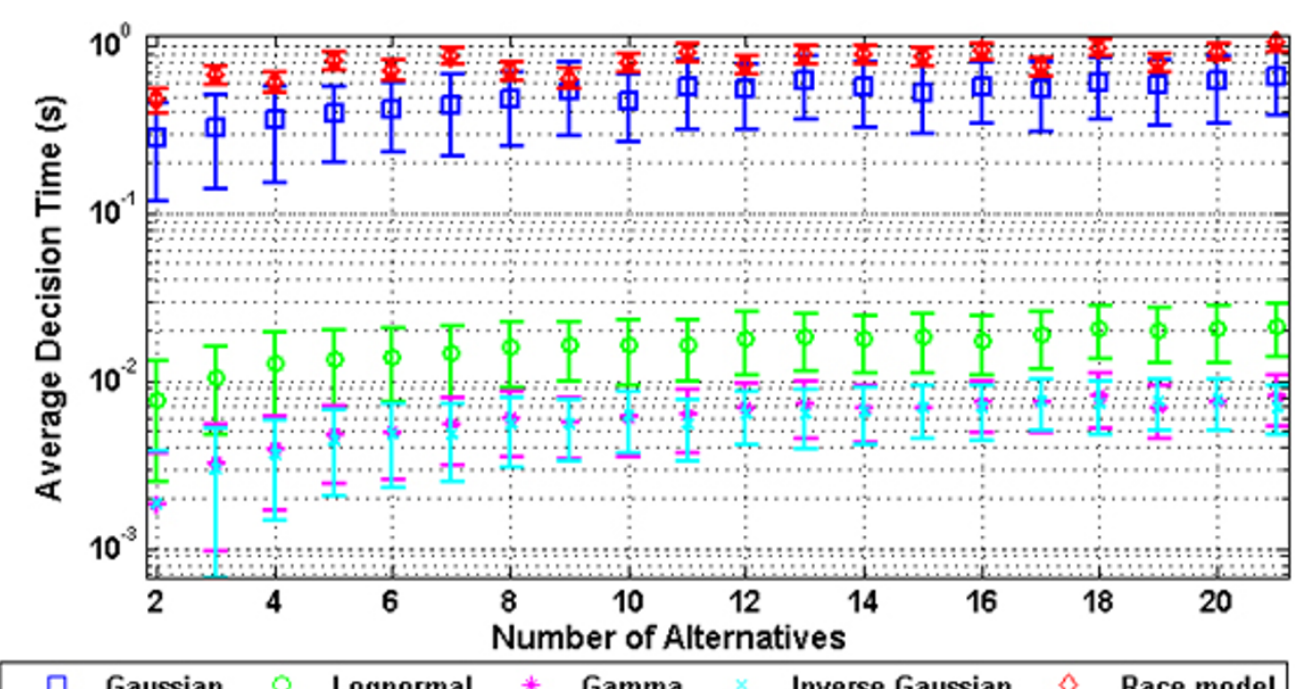

Figure 1 Performance of original Gaussian MSPRT[2], new implementations of MSPRT, and Race model. Performance is measured as decision time against number of alternatives for selection. The selection criterion was $1 \%$ error rate. The results are averaged across 500 simulations and error bars show 1 standard deviation.

\footnotetext{
* Correspondence: j.caballero@shef.ac.uk

Department of Psychology, The University of Sheffield, Sheffield, S10 2TN, UK
} 
across all distributions, together with the so called race model. All variants used the same input statistics (mean and variance). Counterintuitively, the relative performance of the models did not change with base level of salience or evidence.

A critical parameter in the algorithm is the time step $\Delta t$ used to sample the cortical input. The Gaussian, Inverse Gaussian, and Gamma cases are generated as stable Lévy processes and may be scaled indefinitely with decreasing $\Delta t$. However, unlike the MSPRT with Gaussian signals, we show that decision time for the inverse Gaussian, and Gamma decreases with $\Delta t$. Figure 1 use a $\Delta t=1 \mathrm{~ms}$ for all models and clearly shows a performance advantage for the cases with more realistic distributions (the lognormal case is shown with similar scaling even though it has not an associated Lévy process). Indefinitely small decision times may appear unrealistic, but we present an interpretation of cortical sampling that relates $\Delta t$ to the inter-spike intervals of an ensemble of neural afferents impinging on the cortical 'integrators'. This and, other mechanisms, provide a natural lower bound for $\Delta t$. We conclude that neurons may take advantage of the properties of natural spike trains to enhance decision making in the cortex-BG complex.

Published: 20 July 2010

\section{References}

1. Redgrave P, Prescott T, Gurney K: The basal ganglia: a vertebrate solution to the selection problem? Neuroscience 1999, 89:1009-1023.

2. Bogacz R, Gurney K: The basal ganglia and cortex implement optimal decision making between alternative actions. Neural Comput 2007, 19(2):442-477.

doi:10.1186/1471-2202-11-S1-P25

Cite this article as: Caballero and Gurney: Optimal decision making with biologically realistic neural signals. BMC Neuroscience 2010 11(Suppl 1): P25.
Submit your next manuscript to BioMed Central and take full advantage of:

- Convenient online submission

- Thorough peer review

- No space constraints or color figure charges

- Immediate publication on acceptance

- Inclusion in PubMed, CAS, Scopus and Google Scholar

- Research which is freely available for redistribution

Submit your manuscript at www.biomedcentral.com/submit 